\title{
Experience and Enlightenment of Rural Human Resource Development in America
}

\author{
Sishan Zhou \\ College of Marxism, Suzhou University, Anhui, Suzhou, 234000
}

\begin{abstract}
Keywords: Human Resource Development, American Rural Development, Experience and Enlightenment
\end{abstract}

\begin{abstract}
At present, the developed countries attach great importance to the development of rural human resources, a more complete training system and re-education mechanism, in improving the overall quality of agricultural population and speed up the process of rural human resources development has accumulated a wealth of experience. Based on this background, based on summarizing the experience of rural human resources development in the United States, this paper puts forward the establishment of a sound training system for rural human resources development, the strengthening of vocational follow - up education, and the strengthening of rural areas in view of the existing problems in the development of rural human resources in China. The basic education system construction, improve the quality of agricultural population and other countermeasures and suggestions to effectively enhance the coordinated development of Chinese rural regional economic development process, effectively protect the healthy development of Chinese social economy and smooth operation.
\end{abstract}

\section{Introduction}

The development of rural economy can not be separated from the construction of rural human resources. Rural human resources as an important factor of production, rural areas can be coordinated development of the economy to provide personnel protection and intellectual support. Chinese 1.3 billion population, the agricultural population accounted for $70 \%$ of the proportion of rural human resources development work, will greatly improve agricultural productivity, promote the rural economy as a whole "leap-forward" development. Chinese social and economic development is not balanced, farmers' cultural level is relatively low, although basic education has been popular, but the quality of education is generally poor, so the development and training of rural human resources is still a big room for improvement. Developed countries in the development of rural human resources, and promote the coordinated development of rural regional economic practices, including improving the quality of rural labor and the cultivation of diversified skills of these two aspects of talent. Therefore, through the training of education and other forms of rural human resources development work is to improve the overall quality of farmers and promote the process of agricultural modernization of the important content is to achieve the coordinated development of rural regional economy the only way.

\section{Experience in the Development of Rural Human Resources in the United States}

North American model is mechanized farming and scale management of agricultural production, through the construction of a sound agricultural science and education system, to achieve agricultural education, agricultural research and agricultural extension of the organic combination of farmers training model.

In order to improve the education level of peasants, the federal government has established a comprehensive adult education and agricultural extension service system. Short-term training courses, workshops, correspondence education and rural / mobile library 0 are widely available. The federal government has an agricultural cooperation promotion office, the state has a promotion service center, a county promotion station and a promotion committee composed of farmers.

Carry out secondary agricultural education. Setting up agricultural middle schools and 
implementing secondary agricultural education in general secondary schools. In addition, governments at all levels hold annual agricultural gatherings or agricultural expositions, and arrange seminars on agricultural seminars and farmers' concerns to raise awareness of the agricultural resources and the environment.

In addition to the state agricultural colleges, experimental stations and extension stations, the US Department of Agriculture is also an important research institution. Ministry of Agriculture is under the Agricultural Production Bureau, at the establishment of a fairly complete and large agricultural education, research and promotion system.

The US agricultural economy has a strong foundation, high level of science and technology, and the cultivation of agricultural talents focuses on the improvement of scientific skills and comprehensive quality. Specifically, there are several main measures.

Organize technical training. In order to effectively improve the educational level of farmers, improve the technical capacity and the level of operation of mechanized production, the United States from the federal government to establish a complete set of adult education technology training system, each involved in agricultural production labor must accept a certain time Training, and through a certain form of assessment. Only through the assessment, can continue to engage in agricultural production, or we must continue to learn to pay a relatively high amount of tuition. In Texas, for example, the state has established a labor force file for agricultural practitioners, who are required to attend a follow-up training every two years, focusing on the latest agricultural mechanization tools and related regulations. After training, Simple and formal evaluation, only through the person to obtain a certificate of competency, and then engaged in agricultural production. And the file outside the staff is not issued a certificate of competency, nor can not engage in legitimate agricultural production, agricultural products can not get market access. The United States thus established a complete and comprehensive technical training system.

The establishment of a comprehensive agricultural science and education system to speed up the transformation of agricultural science and technology research into the pace and efficiency of productive forces to improve the application of scientific and technological achievements in the proportion of agricultural economic development \# US federal and state government joint funding form, in addition to the construction of agricultural colleges and agricultural science and technology In addition to the experimental station, the Federal Ministry of Agriculture directly responsible for the establishment of the federal state from the state to the vertical management of agricultural science and technology management departments, selected excellent students into the research station, led the local farmers to scientific results of the experiment and into real productivity, Farmers to master the higher technological content of agricultural skills, effective rural human resources development work, and achieved good results through the development of rural human resources, and effectively improve the US agricultural productivity, and promote the regional development of the US agricultural economy.

\section{Analysis on the Current Situation of Rural Human Resource Development in China}

With the development of commodity economy, the problem of poor human resources in rural areas in China has formed a sharp contradiction with the rural economic and social development. Chinese rural areas are from the long-term development of natural resources is gradually turning to the development of human resources. Chinese rural human resources, the status of the specific performance of the following aspects:

According to statistics, by the end of 2010, the urban and rural employment is nearly 790 million people, including rural employment of 470 million people, accounting for $60 \%$ of the total number of employees. According to experts pointed out that during the second five, Chinese new supply of labor is zero. Even with the process of urbanization accelerating, the rural working age population will still account for about $50 \%$ of the total labor force, such a working age population base is equivalent to the sum of the working age population in Europe, up to 500 million people.

Since the reform and opening up, with the development of rural economy, the education level of rural labor has been greatly improved, but the absolute level of its overall quality is still very low, 
mainly in primary school culture, junior high school culture as the main, And the lack of education, it will be difficult to meet the new stage of agricultural development of high-quality agricultural labor force urgent needs. In addition, in the process of improving the quality of rural human resources, it is worth noting that: in addition to many young and middle-aged agricultural labor force is still illiterate and semi-illiterate, there are a considerable part of the young people into the state of employment. These premature minors are potentially illiterate and semi-illiterate, which means the formation of a new generation of illiterate and semi-illiterate.

The loss of excellent labor force in rural areas is the main factor in the development of agriculture. Rural labor surplus is a general concept, but from the perspective of rural labor structure, there are limited, very scarce new farmers with knowledge, culture, mastery of modern agricultural technology and market processes. And this situation continues to move towards a more worsening direction, leading to the loss of excellent labor in rural areas: on the one hand, through the examination, join the army and other ways gone, on the other hand is to work in the city, rather do homeless Do not want to farm again. The labor force left in the countryside is mainly women and the sick and the sick, which poses a greater challenge to the development of rural economy and agriculture.

\section{The Enlightenment of American Rural Human Resources Development to China}

Vigorously develop rural vocational education, cultivate practical talents and skilled talents in rural areas, increase rural human capital stock, promote rural economic and social development and rural labor force transfer. The layout, professional setting and teacher training of rural vocational and technical education must be based on the requirements of the adjustment of agricultural industry structure, the demand of domestic and international labor market, the willingness of farmers to be employed and so on, so that the trained professional and technical personnel can stay Live, need it. Vocational and technical education should be combined with the vocational qualification system, vocational and technical schools should make full use of their own advantages and conditions, and actively carry out adult education for ordinary farmers to carry out vocational and technical training, so that farmers can according to their actual production and employment needs, I want to learn the knowledge and skills, to cultivate. As long as the training is qualified and meet the appropriate vocational qualifications, it should be issued to the corresponding vocational qualification certificate, and by qualification certificate or training to prove that the national and even the international labor market to find employment opportunities.

With a large number of rural surplus labor to the second and tertiary industries, labor income in the income structure of farmers occupy a larger share. To ensure that farmers share the benefits of social welfare in industrialization and urbanization, to ensure that farmers have the ability to participate in market-oriented competition without being marginalized, and to benefit farmers who have not been transferred from agriculture, Industrialization, urbanization and market-oriented job opportunities and competitiveness of the system. The government should gradually break the boundaries between the agricultural population and the non-agricultural population, and provide preferential policies to the farmers in the household registration system and the urban housing, employment, medical, educational and social security systems, and gradually eliminate the rural land system, The establishment of a sound rural labor market, through the formation of a standardized, fully functional market intermediary organizations, for migrant workers to provide employment information for the farmers to provide employment information, , Counseling, vocational training, legal and insurance services to reduce the migrant workers due to blind flow and increase the cost of employment to protect the transfer of rural surplus labor in a reasonable and orderly manner.

At present, rural areas have rich human resources, but the lack of talent. Due to the long-term dual economic structure caused by the differences between urban and rural areas, rural economic development lag, a high level of human capital in rural areas can not be a reasonable reward. On the one hand, in order to pursue higher human capital gains, high-quality rural labor force will naturally flow to the high rate of human capital and economic development of the region. On the other hand, 
rural families live frugally, invest in their children's education is to let their children leave the countryside, to work in the city, rather than after returning to rural areas, for the rural economic development services. With the large number of young adults and the relatively high quality of the labor force to leave the land, the phenomenon of agricultural hollowing is increasingly apparent, affecting the sustainable development of agriculture. Therefore, only the implementation of industrial nurturing agriculture, urban support for rural measures to speed up rural infrastructure construction, speed up rural economic development, improve rural human capital investment rate of return in order to attract rural students to return home to attract urban surplus and rural economy The development of the necessary personnel to rural entrepreneurship.

\section{Conclusion}

From the experience of foreign rural human resources development and from the perspective of building a socialist harmonious society in China, only under the guidance of the scientific concept of development, fully explore and use the rural population productivity, improve the overall quality of the rural population, to play the majority of farmers socialism The main force of the new rural construction in order to promote the rural social and economic development and efficient development in order to achieve the development of production, well-off life, rural civilization, clean and tidy village, the management of democratic new socialist countryside construction goals.

\section{Acknowledgements}

National Social Science Fund Project: a new round of land circulation in Chinese rural human resources development issues

No.: 12BJY040

\section{References}

[1] Teng Yucheng, Wang Ming. Urban and rural integration under the rural human resources development system [J]. Southeast academic, 2013 (06)

[2] Li Yi. Foreign human resources development experience in rural research [J]. World Agriculture, $2013(05)$

[3] Li Gangzi, Qiu Fangfang. Chinese and foreign new rural human resources development model [J]. World Agriculture, 2012 (11)

[4] Wang Wenfeng. Rural human resources development and rural industrial structure adjustment of interactive development research [J]. Academic Forum, 2012 (09)

[5] Li Yusong. Developed countries to promote rural human resources development experience and reference [J]. Agricultural economy, 2011 (12)

[6] Sun Jinhua, Wu Xiaolong. Study on rural human resources development policy under the government - led vision [J]. Journal of Inner Mongolia Agricultural University, 2011 (05) 